\title{
Inventarisasi Kepiting Air Tawar (Brachyura) di Cabang Panti Taman Nasional Gunung Palung Kalimantan Barat
}

\author{
Ina Idola ${ }^{1}$, Junardi ${ }^{1}$, Tri Rima Setyawati ${ }^{1}$ \\ ${ }^{1}$ Program Studi Biologi, Fakultas MIPA, Universitas Tanjungpura, Jl. Prof. Dr. H. Hadari Nawawi, Pontianak, \\ Email korespondensi : inaidola39@yahoo.com
}

\begin{abstract}
Freshwater crabs have an important role in maintaining the balance of the ecosystem. The purpose of research is to know the freshwater crabs and habitat characteristics of Cabang Panti Research Station in Gunung Palung National Park, Kayong Utara Regency. We use a purposive Random sampling and hand collecting methods to inventory of the freshwater crabs. The Cabang Panti Research Station has a three species of freshwater crabs, namely Parathelphusa maindroni, Terrathelphusa sp. and Isolapoamon spatha. Parahelphusa maindroni is the most abundance in freshwater swamps and alluvial habitat.
\end{abstract}

Kata Kunci: Freshwater crabs, Gunung Palung National Park, habitat characteristics, Parathelphusa maindroni

\section{PENDAHULUAN}

Kepiting merupakan hewan invertebrata dari Ordo Decapoda, Subordo Brachyura dengan habitat yang tersebar di perairan payau, laut dan tawar. Peran ekologis kepiting air tawar sangat penting dalam menjaga keseimbangan ekosistem (Rusmadi, 2014). Menurut Ng (2004), kepiting air tawar yang ada di Asia sebanyak 35,71\% famili dan di Asia Tenggara sebanyak 21,43\% famili. Famili kepiting air tawar di Jawa, Borneo dan Sumatera yang telah ditemukan adalah Parathelphusidae dan Sesarmidae (Ng,1997). Berdasarkan data dari International Unit Conservation Natural (IUCN, 2001), di Asia Tenggara terdapat 414 spesies dan di Indonesia terdapat 83 spesies kepiting air tawar. Kepiting air tawar termasuk ke dalam daftar merah atau terancam punah berdasarkan data IUCN (2001). Hal tersebut dapat terjadi karena jumlah individu sedikit dalam populasi kepiting air tawar yang terbatas (Yeo et al., 2008).

Cabang Panti (CP) termasuk kawasan konservasi di Taman Nasional Gunung Palung. Kawasan ini juga termasuk area yang sangat unik karena mempunyai tipe habitat yang beragam diantaranya habitat rawa gambut, rawa air tawar, batu berpasir dataran rendah, alluvial, pengunungan, granit dataran rendah serta dataran tinggi.

Saat ini deforestasi telah terjadi di kawasan CPTNGP baik secara alami maupun akibat pembalakan liar. Hal tersebut dapat menganggu habitat kepiting air tawar karena kepiting air tawar cenderung mencari habitat yang cocok sebagai tempat berlindung dan mencari makan. Tujuan dari penelitian ini untuk mengkaji tentang jenis kepiting air tawar dan karakteristik habitat kepiting air tawar di kawasan Cabang Panti Taman Nasional Gunung Palung, Kayong Utara.

\section{BAHAN DAN METODE}

\section{Waktu dan Tempat}

Penelitian ini dilaksanakan pada bulan Januari sampai Maret 2017. Waktu sampling dilakukan jam 18.30-22.00 WIB. Identifikasi sampel dilakukan di Laboratorium Zoologi Jurusan Biologi, Fakultas Matematika dan Ilmu Pengetahuan Alam.

\section{Alat dan Bahan}

Alat yang digunakan dalam penelitian ini adalah termometer, mikroskop majemuk Olympus CX21, jangka sorong digital (Caliper Mitutoyo Absolute) dan ATK. Bahan yang digunakan adalah alkohol $70 \%$ dan formalin $10 \%$.

\section{Metode}

Penelitian dilakukan di Stasiun Penelitian Cabang Panti, Taman Nasional Gunung Palung, Kayong Utara, Kalimantan Barat pada koordinat $1^{\circ} 13^{\prime}$ LS$101^{\circ} 07^{\prime} B T$. Stasiun penelitian ditentukan dengan 
metode purposive random sampling berdasarkan perbedaan rona lingkungan dan keberadaan perairan sungai. Penelitian ini menetapkan empat habitat sebagai stasiun yaitu habitat granit dataran rendah, batu berpasir dataran rendah, rawa air tawar dan alluvial (Gambar 1).

Pengambilan sampel dilakukan dengan metode road sampling, secara manual (hand collecting) dan diambil menggunakan alat bantu serokan. Road sampling disesuaikan dengan kondisi perairan yang dapat dilalui dengan berjalan kaki. Sampel yang ditangkap diambil gambar yang sudah diukur dan dilakukan pengamatan morfologi. Sampel diawetkan dengan cara direndam formalin $10 \%$ dan alkohol 70\%, kemudian diidentifikasi di Laboratorium Zoologi.

Identifikasi dilakukan sampai tingkat spesies menggunakan buku panduan Ng (2004). Kepiting yang ditemukan diamati dan diukur karakter meristik dan morfometrik. Pengukuran morfometrik kepiting dilakukan dengan mengukur 12 karakter yaitu Lebar Karapas (LK), Lebar Karapak Posterior (LKP), Panjang Karapaks (PK), Jarak antar mata (JAM), Tinggi tubuh (TT), Lebar thorax (LT), Lebar abdomen (LA), Panjang Propodus (PP),
Panjang Dactylus (PD), Lebar Chela (LC), Tinggi Chela (TC) dan Lebar Bukaan Chela (LBC) dapat diamati pada Gambar 3.3 (Windarti, 2002).

Parameter lingkungan yang diamati adalah suhu air, kecepatan arus dan tipe substrat. Tipe substrat diamati secara visual.

Data jenis-jenis kepiting air tawar dari pengamatan morfologi dan morfometrik dianalisis secara deskriptif. Data untuk mengamati karakteristik morfometrik kepiting pembeda antara jantan dan betina menggunakan Analisis Uji $t$ Independent.

\section{HASIL DAN PEMBAHASAN}

\section{Hasil}

Jumlah kepiting air tawar yang berhasil diperoleh sebanyak 60 individu, yang terdiri atas dua famili yaitu Parathelphusidae dan Potamidae dengan tiga spesies yaitu Parathelphusa maindroni, Terrathelphusa sp., dan Isolapotamon spatha. $P$. maindroni merupakan spesies yang paling banyak ditemukan (86,66\%), Terrathelphusa sp., dan $I$. spatha (Gambar 2).

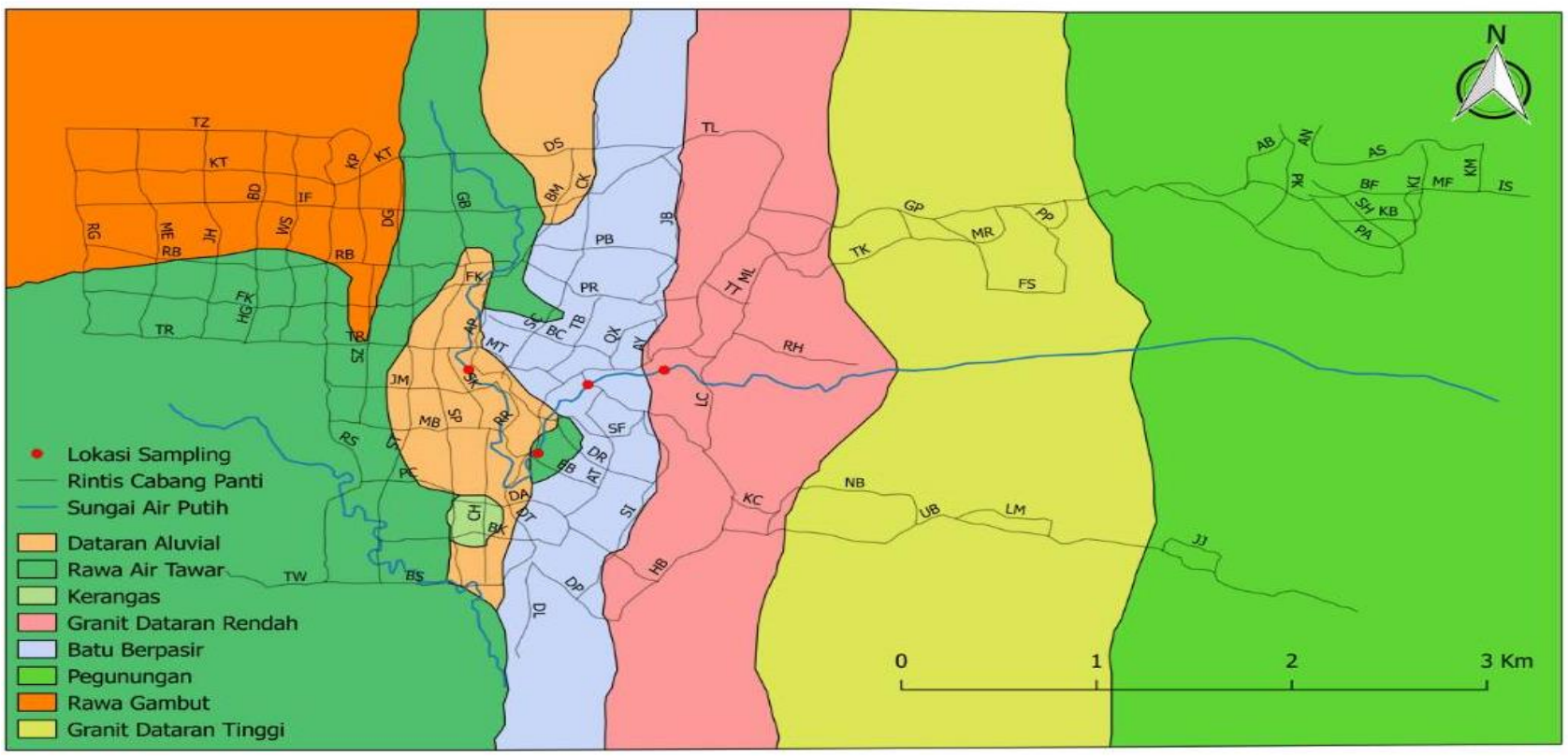

Gambar 1. Lokasi Pengambilan Sampel di Cabang Panti Taman Nasional Gunung Palung. 


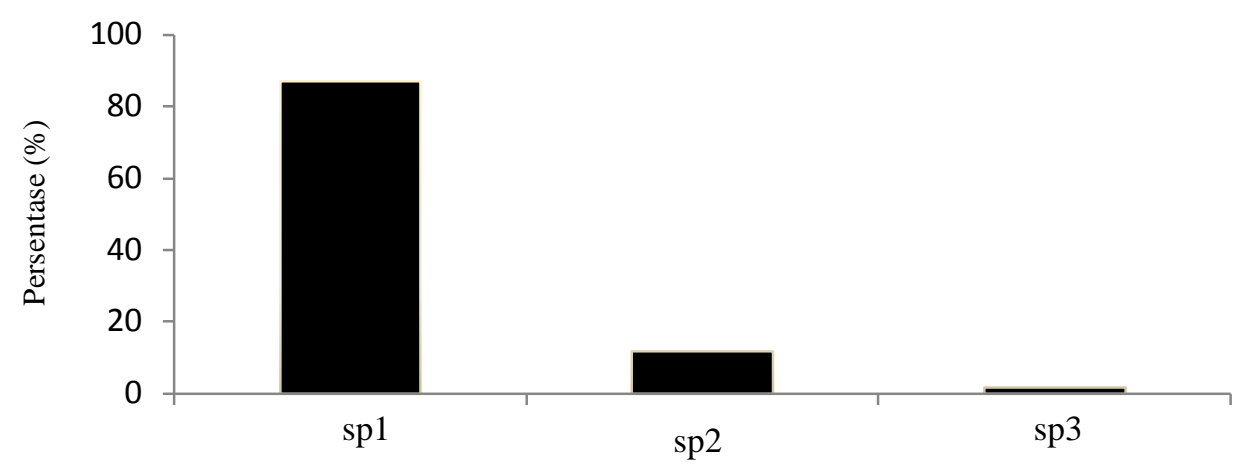

Gambar 2. Persentase Kepiting Air Tawar yang ditemukan di Stasiun Penelitian Cabang Panti. Keterangan sp1 (Parathelphusa maindroni), sp2 (Terrathelphusa sp.), sp3 (Isolapotamon spatha).

Kepiting air tawar jantan ditemukan sebanyak 39 individu dan betina sebanyak 21 individu (Tabel 1). Kepiting air tawar yang ditemukan

di lokasi penelitian mempunyai karakteristik morfologi yang berbeda (Gambar 3 sampai Gambar 5).

Tabel 1. Jumlah Individu Kepiting Air Tawar Jantan dan Betina yang Ditemukan pada MasingMasing Stasiun Penelitian Cabang Panti.

\begin{tabular}{|c|c|c|c|c|c|c|c|}
\hline \multirow[t]{3}{*}{ Stasiun } & \multicolumn{6}{|c|}{ Spesies } & \multirow[t]{3}{*}{$\sum$} \\
\hline & \multicolumn{2}{|c|}{ I. spatha } & \multicolumn{2}{|c|}{ P.maindroni } & \multicolumn{2}{|c|}{ Terrathelphusa sp. } & \\
\hline & $\hat{O}^{\lambda}$ (Ind) & q (Ind) & $\hat{\partial}$ (Ind) & q (Ind) & $\hat{O}($ Ind) & q (Ind) & \\
\hline 1 & 1 & - & - & - & - & - & 1 \\
\hline 2 & - & - & - & - & - & - & - \\
\hline 3 & - & - & 13 & 11 & 3 & 4 & 31 \\
\hline 4 & - & - & 22 & 6 & & & 28 \\
\hline Total & 1 & & 35 & 17 & 3 & 4 & 60 \\
\hline
\end{tabular}

Keterangan : Stasiun 1 (Granit Dataran Rendah), Stasiun 2 (Batu Berpasir Dataran Rendah), Stasiun 3 (Rawa Air Tawar) dan Stasiun 4 (Alluvial), Tanda ${ }^{3}:$ Jantan, $q$ : Betina

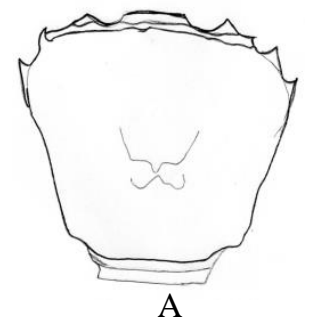

A

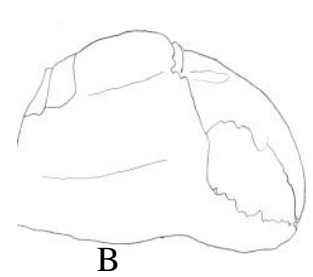

B

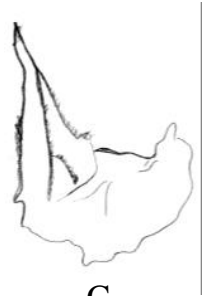

$\mathrm{C}$

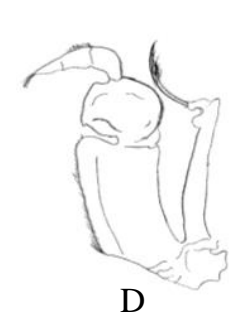

$\mathrm{D}$

Gambar 3. Sketsa Morfologi P. Maindroni yang Ditemukan di Stasiun Penelitian Cabang Panti. Keterangan Gambar A. Bentuk Karapaks dengan 3 Gigi Termasuk Gigi pada Eksternal Orbital, B. Bentuk Dactylus Dewasa Mempunyai Celah yang Lebar dan Bergerigi, C. Pleopod Jantan di Bagian Ujung Meruncing, D. Maxiliped Ketiga Mempunyai Flagellum yang Panjang, Terdapat Rambut Halus, Bagian Merus Membulat dengan Dactylus Meruncing Pendek. 


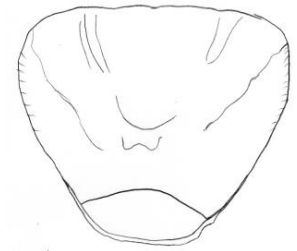

A

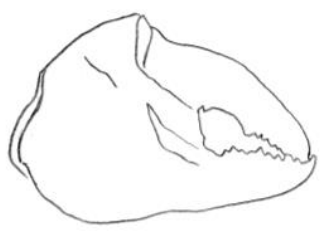

B

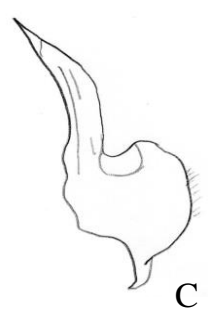

$\mathrm{C}$

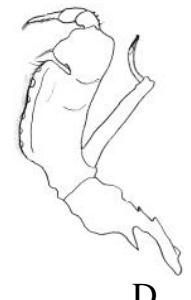

$\mathrm{D}$

Gambar 4. Sketsa Morfologi Terrathelphusa sp., yang Ditemukan di Stasiun Penelitian Cabang Panti. Keterangan Gambar A. Karapaks Tanpa Gigi B. Dactylus C. Male First Pleopods atau Pleopod Pertama Jantan dengan Bentuk Meruncing di Bagian Ujung dan Ukurannya Pendek, D. Maxiliped Ketiga Mempunyai Flagellum Panjang dan Rambut Halus pada Ujung Dactylus.

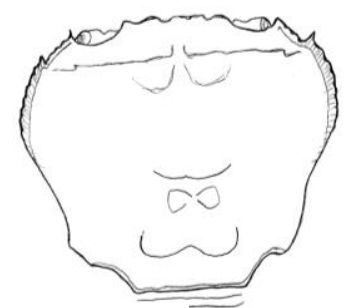

A
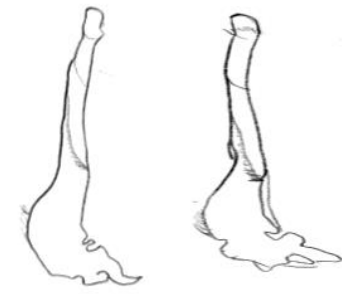

B

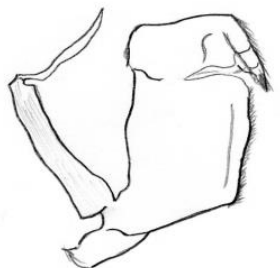

$\mathrm{C}$

Gambar 5. Sketsa Morfologi Kepiting Air Tawar I. Spaha yang Ditemukan di Stasiun Penelitian Cabang Panti. Keterangan Gambar A. Karapaks Mempunyai 2 Gigi, B. Male First Pleopods atau Pleopod Pertama Jantan dengan Bentuk Tumpul di Bagian Ujung, C. Maxiliped Ketiga Mempunyai Flagellum Panjang dan Rambut Halus pada Ujung Dactylus.

Hasil pengukuran faktor lingkungan di stasiun penelitian meliputi suhu perairan $25^{\circ} \mathrm{C}$, kecepatan arus berkisar $0,1-0,5 \mathrm{~m} /$ detik dan tipe substrat (Tabel 2).

Tabel 2. Faktor Lingkungan di Stasiun Penelitian Cabang Panti Taman Nasional Gunung Palung

\begin{tabular}{lllll}
\hline Parameter Lingkungan & \multicolumn{4}{c}{ Stasiun Penelitian } \\
\cline { 2 - 5 } & \multicolumn{1}{c}{ I } & II & III & IV \\
\hline Suhu perairan $\left({ }^{\circ} \mathrm{C}\right)$ & 25,00 & 25,00 & 25,00 & 25,00 \\
Kecepatan arus $(\mathrm{m} / \mathrm{det})$ & $0,5-0,33$ & $0,33-0,25$ & $0,125-0,1$ & $0,11-0,1$ \\
Tipe substrat & Berbatu besar & Berbatu & Berbatu & Pasir berserasah
\end{tabular}

Keterangan: Stasiun I (Granit Dataran Rendah), Stasiun II (Batu Pasir Dataran Rendah), Stasiun III (Rawa Air Tawar) dan Stasiun IV (Alluvial).

\section{Pembahasan}

Kepiting air tawar ditemukan pada tiga habitat dari empat habitat di perairan Stasiun Penelitian Cabang Panti. Satu spesies yaitu Isolapotamon spatha dari Famili Potamidae ditemukan di habitat granit dataran rendah. Cumberlidge et al. (2009), menyatakan bahwa Famili Potamidae merupakan famili terbesar dengan jumlah 505 spesies. Habitat granit dataran rendah mempunyai arus deras dengan kecepatan antara $0,5-0,33 \mathrm{~m} /$ detik, kadar oksigen terlarut $6,28-7,2 \mathrm{mg} / \mathrm{L}, \mathrm{pH} 6,5$, substrat batuan besar dan perairan jernih.
Grinang \& Ng (2015), menyatakan bahwa Isolapotamon mempunyai karakter habitat dengan perairan berarus deras, jernih, mengandung banyak oksigen terlarut dan substrat batuan besar. Rona lingkungan tersebut mampu mendukung kehidupan kepiting air tawar. Eprilurahman et al. (2015), menyatakan bahwa Potamidae hanya dapat hidup pada perairan tawar.

Kepiting air tawar Parathelphusa maindroni paling banyak ditemukan di lokasi penelitian. Hal ini sesuai dengan penelitian Ng (2004), yang menyatakan bahwa Parathelphusidae 
merupakan famili yang banyak ditemukan karena mampu beradaptasi di daratan rendah hingga daerah pegunungan dan mulai dari perairan mengenang sampai di habitat terestrial. P.maindroni paling banyak ditemukan pada habitat alluvial yang memiliki substrat berpasir dan arus lambat. Menurut Taufik (2011), banyaknya individu yang diperoleh pada suatu habitat menunjukkan kondisi lingkungan tersebut cocok untuk kehidupan jenis ini.

Eprilurahman et al. (2015), menyatakan bahwa Parathelphusa dapat dijumpai pada habitat dengan tipe substrat yang beragam seperti batuan, pasir dan lumpur. Kecepaan arus di habitat alluvial mempunyai kisaran $0,11-0,1 \mathrm{~m} /$ detik, kadar oksigen terlarut berkisar 5,52-6,07mg/ L dan $\mathrm{pH} 6,0$. Chua et al. (2015), menyatakan bahwa untuk $\mathrm{pH}$ lingkungan yang dapat mendukung keberadaan Parathelphusa berkisar 4,54-7,60 atau sering ditemukan dengan kadar $\mathrm{pH} 5,06-$ 6,31 .

Chua et al. (2015), juga menyatakan bahwa Parathelphusa dapat juga ditemukan pada arus perairan lambat dan $\mathrm{pH}$ yang asam. Sedangkan kadar oksigen terlarut yang baik untuk Parathelphusa berkisar 70,44-88,85\%. Selain itu, habitat alluvial mempunyai vegetasi di tepi perairan yang rindang dan suhu perairan $24^{\circ} \mathrm{C}$. $\mathrm{Ng}$ (1997), menyatakan bahwa Parathelphusa banyak dijumpai pada sungai yang terlindungi vegetasi pohon yang rindang dengan suhu udara maupun suhu air yang rendah. Riadi et al. (2014), menyatakan bahwa vegetasi yang rapat dapat menjadi tempat bersembunyi yang baik dari predator.

Kepiting air tawar Parathelphusa maindroni dan Terrathelphusa sp., ditemukan di habitat rawa air tawar. Menurut Ng (2004), Parathelphusa adalah genus yang umum ditemukan di Kalimantan karena memiliki persebaran yang luas. Freitag \& Yeo (2004), juga menyatakan bahwa kepiting air tawar yang mendominasi adalah Parathelphusa yang ditemukan pada substrat batuan di sungai dan danau di Filipina.

Terrathelphusa sp., ditemukan pada substrat lumpur. Grinang \& Ng (2015), menyatakan bahwa kepiting air tawar Terrathelphusa sp., dapat ditemukan pada semua tipe habitat sungai dengan suhu air dan suhu udara rendah, substrat batuan atau lumpur dan vegetasi yang rapat. suhu perairan di lapangan tercatat $25^{\circ} \mathrm{C}$ dan $\mathrm{pH}$ 5,5. Menurut Fuad (2005), suhu mempunyai peran dalam kehidupan kepiting atau organisme aquatik lain diantaranya untuk respirasi, kestabilan konsumsi pakan, metabolisme, pertumbuhan, tingkah laku, reproduksi dan mempertahankan kehidupan.

Menurut Odum (1981), suhu ekosistem aquatik dipengaruhi oleh intensitas matahari, ketinggian geografis dan tutupan kanopi. Menurut Tatangin et al. (2013), pH yang ideal bagi kehidupan biota air tawar adalah antara 6,80-8,50. Derajat keasaman ( $\mathrm{pH}$ ) yang sangat rendah dapat menyebabkan kelarutan logamlogam dalam air makin besar yang bersifat toksik bagi organisme air sebaliknya $\mathrm{pH}$ yang tinggi dapat meningkatkan konsentrasi amoniak dalam air yang juga bersifat toksik bagi organisme air.

Kepiting air tawar tidak ditemukan di habitat batu berpasir dataran rendah. Habitat batu berpasir dataran rendah mempunyai substrat batuan yang besar, kedalaman air berkisar 26,00-55,00cm dan kecepatan arus perairan antara $0,33-0,25 \mathrm{~m} /$ detik. Kondisi demikian kurang mampu mendukung keberadaan kepiting air tawar. Menurut Rafni (2004), substrat yang kasar tidak ditemukan kandungan bahan organik karena partikel yang halus tidak dapat mengendap.

Morfometrik kepiting air tawar jantan dan beina dewasa pada Parahelphulsa maindroni, Isolapotamon spatha dan Terrathelphusa sp., dilakukan untuk melihat adanya perbedaan morfologi. Spesies P. maindroni di habitat alluvial mempunyai perbedaan karakter pada lebar karapaks, panjang karapaks dan jarak antar mata. Panjang karapaks jantan lebih besar dibandingkan betina. Sedangkan lebar karapaks jantan lebih kecil dibandingkan betina. Riadi et al. (2014), menemukan lebar karapaks dan panjang karapaks jantan lebih besar daripada betina.

Pertumbuhan kepiting dapat ditandai dengan lebar dan panjang karapaks karena adanya pergantian karapaks atau moulting. Wiyanto \& Hartono (2003), menyatakan bahwa moulting 
berfungsi untuk memicu dan mempercepat pertumbuhan. Menurut Rangka \& Suleman (2010), untuk tumbuh menjadi besar kepiting akan melepaskan karapaks yang lama kemudian kulit akan mengeras menjadi karapaks yang baru dengan ukuran yang lebih besar. Secara fisiologis kepiting betina lebih banyak membutuhkan energi untuk persiapan moulting dan pertumbuhan sel telur sehingga energi yang dibutuhkan semakin tinggi.

Jarak antar mata dapat dipengaruhi oleh pertumbuhan kepiting. Mata kepiting dilengkapi oleh tangkai mata. Warner (1977), menyatakan bahwa tangkai mata yang panjang, mungkin digunakan untuk meningkatkan jarak pandang pada dataran yang rata.

Spesies $P$. maindroni di habitat rawa air tawar mempunyai perbedaan pada lebar karapaks, lebar abdomen dan panjang propodus kiri. Berdasarkan morfometrik, jantan mempunyai ukuran lebar karapaks, lebar abdomen dan panjang propodus lebih lebar daripada betina. Menurut Wijaya et al. (2010), kepiting jantan lebih bersifat agresif dalam mencari makanan sehingga energi yang diperoleh untuk aktivitas dan pertumbuhan akan menjadi tinggi. Rangka \& Suleman (2010), menyatakan jantan hanya membutuhkan energi dalam proses maintenance dan recovery saja tanpa mengalokasikan untuk pertumbuhan oosit dalam gonad.

Morfometrik jantan dan betina pada Terrathelphusa sp., mempunyai perbedaan pada karakter lebar karapaks, lebar abdomen dan lebar karapak posterior. Ukuran abdomen betina lebih lebar apabila dibandingkan jantan. Siahainenia (2009), menyatakan bahwa ukuran dan bentuk abdomen serta ruas-ruas pada tutup abdomen merupakan salah satu faktor pembeda dalam identifikasi jenis kelamin kepiting.

Jenis kelamin kepiting jantan dan betina dapat diamati dari bentuk luar tubuh. Berdasarkan morfologi, abdomen jantan mempunyai bentuk 'huruf $T$ ' terbalik dengan bagian ujungnya meruncing sedangkan pada abdomen betina mempunyai bentuk lonceng dengan bagian abdomen lebar dan agak tumpul bagian ujung. Puspitasari (2013), menyatakan kepiting jantan mempunyai organ kelamin yang menempel di bagian perut yang membentuk segitiga meruncing dan betina pada organ kelamin yang cendrung berbentuk segitiga melebar dan bagian depan tumpul. Selain mengamati bentuk abdomen, untuk membedakan jantan dan betina dapat dilakukan dengan mengamati ruas-ruas abdomen.

Kepiting air tawar yang diperoleh pada penelitian ini adalah Parathelphulsa maindroni dan Terrathelphusa sp., dari Famili Parathelphulsidae dan Isolapotamon spatha dari Famili Potamidae. Habitat yang cocok untuk kepiting air tawar adalah lingkungan habitat alluvial, habitat rawa air tawar dan habitat granit dataran. Sedangkan habitat batu berpasir dataran rendah kurang mampu mendukung keberadaan kepiting air tawar.

\section{DAFTAR PUSTAKA}

Chua, KWJ, Ng, DJJ, Zeng, Y \& Yeo, DCJ, 2015, Habitat Characteristic of Tropical Rainforest Freshwater Crabs (Decapoda: Brachyura: Potamidae, Gecarcinucidae) In Singapore", Journal of Crustacean Biology, vol. 35, no.4, hal. 533-539

Cumberlidge, N, Ng, PKL, Yeo, DCJ, Magalhaes, C, Campos, M, Alfarez, F, Naruse, T, Daniel, SR, Esser LJ, Attipoe, FYK, Ba, FLC, Darwal, W, Mclvor, A, Baillie, JEM, Collen, B \& Ram, M, 2009, 'Freshwater Crabs and The Biodiversity Crisis: Importance, Threats, Status, and Conservation Challenges', Biological Conservation, vol. 142, hal. 1665-1673

Eprilurahman, R, Baskoro, WT \& Trijoko, 2015, 'Keanekaragaman Jenis Kepiting (Decapoda: Brachyura) di Sungai Opak, Daerah Istimewa Yogyakarta', Biogenesis, vol. 3, no. 2, hal. 100-108

Fuad, 2005, Strategi dan Program Penelitian Agroindustri Perikanan, Puslibangkan, Jakarta 
Freitag, H \& Yeo, DCJ, 2004, 'Two New Spesies of Parathelphusa H. Milne Ewards, 1853, From The Philippines (Crustacea: Decapoda: Brachyura: Parathelphusidae)', The Raffles Bulletin of Zoology, no. 52, hal. 227-237

Grinang, J \& Ng, PKL, 2015, 'Taxonomy of The Semiterrestrial Crab Lepidothelphusa cognettii (Nobili, 1903) (Crustacea: Decapoda: Brachyura: Gecarcinucidae), with Descriptions of Five New Species From Sarawak, Malaysia, Borneo, The Raffles Bulletin of Zoology, vol. 63, hal.564-582

IUCN, 2001, IUCN Red List Categories and Criteria Version 3.1, IUCN-World Conservation Union, Gland, Switzerland

Langer, S, Tripathi, Khajuria, 2013, Morphometric and Meristic Study of Golden Mahseer (Tor putitora) from Jhajjar Stream India, Journal of Animal, Veterinary and Fishery Sciences, vol.1, no.7, hal. 1-4

Misra, RK \& Easton, MDL, 1999 'A Note on The Number of Morphometric Characters Used in Fish Stock Delineation Studies Employing A MANOVA. Journal Fisheries Research, no. 42, hal. 191-194

Ng, PKL, 1997, 'on A New Genus and Four New Species of Freshwater Crabs (Crustacea: Decapoda: Brachyura: Parathelphulsidae) from Borneo and Java', The Raffles Bulletin of Zoology, vol. 45, no.1, hal. 105-121

Ng, PKL, 2004, 'Crustacea: Decapoda: Brachyura, Freshwater Invertebrata of the Malaysian Region', Department of Biological Sciences, Nasional University of Singapore, Kent Ridge, Singapore

Ng, PKL, Schubart, CD \& Lukhaup, C, 2015, 'New Spesies of "Vampire crabs" (Geosesarma De Man, 1892) from Central Java, Indonesia and Identity of
Sesarma (Geosesarma) Nodulifera De Man, 1892 (Crustacea, Brachyura, Thoracotremata, Sesarmidae)', The Raffles Buletin of Zoology, no. 63, hal. 3-13

Odum, EP, 1981,' Dasar-Dasar Ekologi', Edisi ketiga, Gajah Mada University Press, Original English Edition, Fundamental of Ecology Thurd Edition, Yogyakarta

Rafni R. 2004, Kapasitas Asimilasi Beban Pencemar di Perairan Teluk Jobokuto Kabupaten Jepara Jawa Tengah, Tesis, Institut Pertanian Bogor, Bogor

Rangka, NA \& Sulaeman, 2010 'Pemacuan Pergantian Kulit Kepiting Bakau (Scylla serrata) Melalui Manipulasi Lingkungan untuk Menghasilkan Kepiting Lunak', Prosiding Forum Inovasi

Riadi, R, Mahatma, R, \& Windarti, 2014, 'Inventarisasi Kepiting Air Tawar di Kecamatan Kampar Utara Kabupaten Kampar Provinsi Riau', Jom Fmipa, vol.1, hal. 471-478

Rusmadi, 2014, 'Studi Biologi Kepiting di Perairan Teluk Dalam Desa Malang Rapat Kabupaten Bintan Provinsi Kepulauan Riau', Jurusan Ilmu Kelautan Fakultas Ilmu Kelautan dan Perikanan, Universitas Maritim Raja Ali Haji

Puspitasari, F, 2013, 'Inventarisasi dan Intesitas Ektoparasit pada Kepiting Bakau (Scylla paramamosin) yang Dipelihara di Tambak di Desa Ketapang, Gending dan Pajarakan Kabupaten Probolinggo Jawa Timur', Skripsi, Fakultas Perikanan dan Ilmu Kelautan Universitas Airlangga

Siahainenia, L, 2009, 'Struktur Morfologi Kepititng Bakau', Jurnal Triton, no.1, vol.5, hal. 11-21 
Taufik, 2011, 'Keanekaragaman Udang Air Tawar di Danau Kerinci Provinsi Jambi', Tesis, Institut Pertanian Bogor

Tatangin DF, Kalesaran, O \& Rompas, R, 2013,'Studi Parameter Fisika Kimia Air pada Areal Budidaya Ikan di Danau Tondano', Desa Paleloan, Kabupaten Minahasa

Warner, Gf, 1977, 'The Biology of Crabs'. Eleck Science, London

Windarti, 2002, 'Life History of Sesarma messa (Brachyura, Decapoda and Assessment of The Possibility of Using Lipofuscin to Determine Age', Thesis, James Cook University, Australia

Wijaya, N.I., Yulianda, F, Boer,M \& Juwana, S, 2010, Biologi Populasi Kepiting Bakau (Scylla Serrata F.) di Habitat Mangrove Taman Nasional Kutai Kabupaten Kutai Timur, Oseanologi dan Limnologi di Indonesia, no. 36, vol.3, hal. 439-456

Wiyanto, RH \& Hartono, R, 2003, Lobster Air Tawar: Pembenihan dan Pembesaran, Penebar Swadaya, Jakarta

Yeo, Ng, PKL, 'Cumberlidge, N, Magalhaes, C, Daniel, SR, Campos, MR, 2008, 'Global Diversity of Crab (Crustacea; Decapoda; Brachyura) in Freshwater', Hydrobiologia, vol. 595, hal. 275-286 